\title{
Inhibition of cysteine peptidase activity in ascitic fluid in pancreatic cancer patients
}

\author{
Anil Kumar Agrawal'1, Wojciech Kielan', Abdo Katib², Zgmunt Grzebieniak', \\ Adam Skalski ${ }^{1}$, Tomasz Grzebieniak ${ }^{5}$, Lukasz Duda-Barcik ${ }^{1}$, Anna Janocha ${ }^{4}$, \\ Maciej Siewiński ${ }^{2,3}$
}

\author{
${ }^{1}$ 2nd Department of General and Oncological Surgery, Medical University of Wrocław, Poland \\ ${ }^{2}$ Faculty of Public Health, Medical University of Wrocław, Poland \\ ${ }^{3}$ Beskid College of Skills in Żywiec \\ ${ }^{4}$ Department of Physiology, Medical University of Wrocław, Poland \\ ${ }^{5}$ Department and Clinic of Cardiology, Medical University of Wrocław, Poland
}

\begin{abstract}
The work's objective is to answer the question whether there is any possibility of activity inhibition of cysteine peptidases inhibitors playing an important role in key processes accompanying cancer formation, including pancreas. There is a justified speculation that specific inhibitors of these enzymes may inhibit development of cancer processes by inhibiting their activity. In vitro studies confirmed that these enzymes in ascitic fluid were inhibited with egg whites inhibitors even to $90 \%$ of their original activity.
\end{abstract}

Key words: pancreatic cancer, cystatin, egg white, ascitic fluid

\section{Introduction}

Every year more than 250,000 people develop pancreatic cancer. Because no effective treatment for the disease has been found, the mortality rate is practically $100 \%$ [1].

The spread of the neoplasm in the abdominal cavity leads to the development of ascites, which is a complex process. Both the increased permeability of the microcirculation system of the tumour and its very presence intensify the production of ascitic fluid. The aggressiveness of the neoplasm and the development of metastasis largely depend on the vascular endothelial growth factor (VEGF) and the vascular permeability factor (VPF) [2-4].

The characteristic conditions under which ascitic fluid caused by neoplastic changes is produced have led to the development of a method for intraperitoneal administration of antineoplastic drugs [5].

Correspondence: A.K. Agrawal, 2nd Department of General and Oncological Surgery, Borowska Str. 213, Medical University of Wrocław, 50-556 Wrocław, Poland;

tel. (+48) 609289027, e-mail: dranilpreeti@gmail.com
Almost entire doses of conventional synthetic cytostatics are absorbed from the peritoneum by blood and so doses used in intraperitoneal treatment are identical to those administered intravenously. In some cases ascitic fluid may prove helpful in designing new methods of treatment for this cancer consisting in intraperitoneal administration of cytostatics [2]. Intraperitoneal chemotherapy uses cytostatics that have a small molecular weight and so penetrate through the membrane separating ascitic fluid from the patient's blood, making their way into the blood and causing the same side effects as in the case of intravenous chemotherapy. Intraperitoneal treatment is used for neoplasms of the ovary, pancreas or liver [6,7].

Toxic cytostatics administered intraperitoneally even in doses many times exceeding standard intravenous doses have been shown experimentally not to irritate the peritoneum or cause systemic toxicity. However, they do not seem to have satisfactory treatment effectiveness. For some time now synthetic tissue metaloproteinase inhibitors (TIMPs) have been utilised in intravenous and intraperitoneal treatment; these are used by tumour cells to destroy and remodel tissue stroma as part of metastasis, but they also block 
angiogenesis, stopping local infiltration, and enable tumor encapsulation $[8,9]$.

An important role in neoplastic processes is also played by proteolytic enzymes. Their activity has been found to increase with the expression of the neoplasm, its metastasis, angiogenesis and when controlling apoptosis of neoplastic cells [10].

Overexpression of proteolytic enzymes belonging to cysteine peptidases (cathepsins $\mathrm{B}, \mathrm{L}$ or $\mathrm{K}$ ) is mainly to be found within the border zone between neoplastic and healthy tissue, as well as in systemic fluids accompanying such changes. Their high activity has been observed in ascitic fluid caused by the development of the neoplasm.

Their activity is controlled in vivo by autogenous inhibitors produced by the body. Overexpression of such enzymes has been found at places where neoplastic changes occur, but the amount of own inhibitors is insufficient to stop carcinogenesis [11].

Another approach to developing new treatments is represented by inhibitors of cysteine peptidases, which are used to arrest the activity of neoplastic cathepsins B, $\mathrm{K}$ and $\mathrm{L}$. These are able to block the activity of enzymes determining the activation of apoptosis of cancerous cells and to control invasion, metastasis and angiogenesis. The fact that cysteine peptidases forming inactive complexes are present in the body attests to the existence in the body of defensive factors, including autogenous inhibitors (cystatins or kininogens), but their activity is hindered by overexpression of cysteine peptidases or other substances accompanying the neoplastic process. This suggests that an excess of cysteine peptidases related to the neoplastic process may be limited by introduction into the body of cysteine inhibitors, as this strengthens the autogenic immune system [12].

Changes in the activity of peptidases have also been observed in neoplastic change processes that accompany the development of pancreatic cancer [13].

The lack of an effective treatment means that research into new pancreatic cancer therapies should be intensified. The study focused on the use of cystatins isolated from chicken egg white to inhibit the activity in ascitic fluid of cysteine peptidases, the enzymes that induce the key neoplastic processes. The delivery of inhibitors through ascitic fluid should limit their potential side effects on the patient. Furthermore, because of the size of its molecule, the inhibitor should not be able to permeate the membrane that keeps ascitic fluid separate from other body fluids and act within the ascitic water-neoplasm area.

\section{Materials and methods}

Biological material. The ascitic fluid needed for the study was collected from patients with ascites treated for pancreatic cancer. Fluid samples were taken from 31 patients with diagnosed pancreatic cancer. The samples had a volume of $5.0 \mathrm{ml}$ each; they were first frozen at $-20^{\circ} \mathrm{C}$, then defrosted and centrifuged at $10,000 \mathrm{rpm}$. The obtained deposit was separated, to be used for cytological examination, and the supernatant was frozen at $-20^{\circ} \mathrm{C}$. The deposit was checked cytologically for the presence of cancerous cells. The supernatants were refrozen at $-20^{\circ} \mathrm{C}$ and kept for further determinations. After defrosting they were first examined for the activity of cysteine peptidases and then the activity was arrested with a specific inhibitor - cystatin from chicken egg white. The pure and sterile inhibitor was dissolved in physiological saline and used in titration of cystein peptidases in the ascitic fluid supernatant.

Cysteine proteinase inhibitor (CPI, cystatin) was isolated from eggs as previously described [14].

Measurement of the activity of cysteine peptidases by spectrofluorometry. The activity of cysteine peptidases was measured with a Perkin Elmer UV/VIS Spectrometer Lambda Bio 20 (Perkin Elmer, Wellesley, MA, USA). One sample contained $100 \mu$ of ascities fluid, diluted with normal saline as needed according to the concentration of the enzyme; $700 \mu 10.4 \mathrm{M}$ phosphate buffer at $\mathrm{pH}$ 6.0 , including $4 \mathrm{mM}$ ethylenediamine tetraacetic acid (EDTA), $2.5 \mathrm{mM}$ dithiothreitol (DTT), and $200 \mu$ ldiluted substrate concentrate Z-Phe-Arg-NMec, whose concentration was $40 \mu \mathrm{M}$. The sample was incubated at $37^{\circ} \mathrm{C}$ for $60 \mathrm{~min}$. The reaction of hydrolysis was terminated by adding $2.0 \mathrm{ml}$ of $1.0 \mathrm{mM}$ iodoacetic acid to each sample. Fluorescence of the liberated 7-amino-4-methylcoumarin (Mec) was measured using the wavelength $\lambda=370 \mathrm{~nm}$ for excitation and $\lambda=440 \mathrm{~nm}$ for emission. The measurements were made in regard to baseline solution, which differed from the analyzed samples in that $2.0 \mathrm{ml}$ of iodoacetic acid was added before the substrate. The results are given in units of activity of cysteine endopeptidases, calculated for the amount of protein appearing in the sample. One unit of enzyme activity was defined as that amount of the enzyme that would liberate $1 \mathrm{nM}$ of Mec per $1 \mathrm{~min}$, calculated for $1 \mathrm{mg}$ of protein

Determination of cathepsin B-like activity. Cathepsin B activity was measured in $100 \mu \mathrm{l}$ of ascitic fluid supernatant according to Barretts method. One $\mathrm{mEU}$ of activity was defined as the quantity releasing $1 \mathrm{nM}$ of 7 -AMC $[15,16]$.

Inhibition of cathepsin B with egg white cystatin. Initially, various amounts of egg white cystatin $(25 \mu \mathrm{g}, 50 \mu \mathrm{g}$ and $100 \mu \mathrm{g})$ were added to $100 \mu \mathrm{l}$ samples of ascitic fluid in order to determine its optimum amount. $100 \mu 1$ samples of ascites fluid supernatant were added to $500 \mu \mathrm{l}$ of $0.4 \mathrm{M}$ sodium phosphate activation buffer $(\mathrm{pH}$ 6.0) containing $4 \mathrm{mM}$ EDTA, $2.5 \mathrm{mM}$ DTT, and were subsequently preincubated for $5 \mathrm{~min}$ at $37^{\circ} \mathrm{C}$ before the addition of $100 \mu \mathrm{l}$ of a solution containing $100 \mu \mathrm{g}$ protein of egg white cystatin. The samples were incubated for 10 minutes at $37^{\circ} \mathrm{C}$ and than $100 \mu \mathrm{l}$ of $200 \mu \mathrm{M}$ Z-Arg-AMC and the incubation was carried out for $30 \mathrm{~min}$ and stopped by the addition of $2 \mathrm{ml}$ of $1 \mathrm{mM}$ iodoacetic acid. Fluorescence was measured at $370 \mathrm{~nm}$ excitation and $440 \mathrm{~nm}$ emission wavelengths using a Luminescence Spectrometer, Perkin Elmer LS $50 \mathrm{~B}$. One $\mathrm{mEu}$ of inhibitor activity was defined as a quantity of cathepsin B releasing $1 \mathrm{nM}$ of 7-AMC [14,17].

Statistical analysis. The data were expressed as the mean values \pm SD. Walloon's rank test were used. The 0.05 level of probability was assumed as significant.

\section{Results}

Determinations were made for supernatants of ascitic fluid taken from 31 patients with pancreatic cancer.

First, the activity of cysteine peptidases in the fluid was determined. Using Z-Arg-AMC as a substrate, total 
Table 1. Inhibition with egg white cystatins of cysteine peptidase activity in three ascitic fluid samples obtained from pancreatic cancer patients.

\begin{tabular}{|c|c|c|c|}
\hline $\begin{array}{c}\text { Cystcinc } \\
\text { peptidase } \\
\text { activity/l.0 } \mathrm{ml}\end{array}$ & $\begin{array}{c}+25 \mu \mathrm{g} \\
\mathrm{ICP} / 1.0 \mathrm{mg} \\
\text { protcin }\end{array}$ & $\begin{array}{c}+50 \mu \mathrm{g} \\
\mathrm{ICP} / 1.0 \mathrm{mg} \\
\text { protcin }\end{array}$ & $\begin{array}{c}+100 \mu \mathrm{g} \\
\mathrm{ICP} / 1.0 \mathrm{mg} \\
\text { protcin }\end{array}$ \\
\hline 205.8 & $32.12 \%$ & $68.77 \%$ & $96.47 \%$ \\
\hline 282.5 & $29.56 \%$ & $52.43 \%$ & $95.14 \%$ \\
\hline 241.1 & $23.87 \%$ & $62.26 \%$ & $96.44 \%$ \\
\hline
\end{tabular}

activity of cathepsins $\mathrm{B}, \mathrm{L}$ and $\mathrm{K}$ was determined. Afterwards three fluid samples were selected at random in order to establish the optimum amount of egg white cystatin for inhibiting cysteine peptidase activity so that 10$30 \%$ of the original activity remained. Cystatin was isolated from egg white by means of our own method.

In order to assess the degree of inhibition of enzyme activity various amounts of egg white cystatin with an activity of $64.8 \mathrm{mEU} /$ protein were added to the three samples. The inhibitor was added in the amounts of $25 \mu \mathrm{g}, 50 \mu \mathrm{g}$ and $100 \mu \mathrm{g}$. The best results were obtained when $100 \mu \mathrm{g}$ of the inhibitor were used. The test results are presented in Table 1 . The activity of cysteine peptidases in all ascitic fluid samples was most effectively reduced when $100 \mu \mathrm{g}$ of egg white cystatin was added. The results are given as percentages of inhibition of the activity of the cysteine peptidases in question. The activity of the enzymes in the fluids under study was reduced by $70-95 \%$. The results are presented in Fig. 1 and Fig. 2.

\section{Discussion}

The study was aimed at determining the arrest of neoplastic processes. It was conducted in two directions. The first focused on establishing the ability to control the vascular endothelial growth factor (VEGF) and the vascular permeability factor (VPF). The protein is responsible for angiogenesis in neoplastic tissue. It affects the exchange of the products of metabolism and a reduction in its concentration may lead to necrosis of neoplastic tissue. A rise in its concentration facilitates the growth and nourishment of pathogenic tissue, which is related to angiogenesis [18]. It seems that a reduction in VEGF protein or its receptor may be used as a therapy in neoplastic patients. In tissue unable to nourish itself and remove the products of metabolism there develops necrosis, which in this case has a therapeutic effect. The protein, as indicated above, is even regarded as a prognostic marker associated with neoplasms [19].

Changes in the protein concentration have also been observed in the case of pancreatic cancer; they can be induced by metaloproteinase inhibitors or the specific protein antineoplastic drug Bevacizumab. It is a new generation drug guided on the basis of the antigen/antibody affinity. It is a humanized monoclonal antibody used for blocking vascular endothelial growth factor $\mathrm{A}$ and is regarded as an angiogenesis inhibitor $[20,21]$.

The other part of the study concentrated on the role of proteolytic enzymes and an attempt to control them. It was found that a number of proteolytic enzymes control the major stages leading to the development of neoplasm. The key role in such processes is played by cysteine peptidases. The enzymes mutually activate one another and in the end result in the development of neoplasm. The activity of the enzymes may be controlled with specific inhibitors. Understanding the processes may lead to the development of new treatments for cancer $[22,23]$.

Big hopes rest on the use of cystatins for controlling neoplastic processes such as invasion, metastasis and angiogenesis. Using the inhibitors it is not only possible to control enzymatic changes but also VEGF [24,25].

Of special importance to the arrest of the activity of cathepsins B, K and L are egg white cystatins. The inhibitors have been found to control in vitro the activity of the enzymes in cancerous tissue homogenates in patients operated for malignant neoplasms of the digestive track [26].

It has even been discovered that by using immunohistochemical tests it is possible to determine egg cystatin-cathepsin B levels in neoplastic tissue [27].

It may also be assumed that egg white cystatin may be used to control the activity of cysteine peptidases that is closely connected with neoplastic processes, as the protein is structurally similar to autogenous inhibitors controlling the overexpression of cysteine peptidases [28].

It has also been observed that when animals with human neoplasms receive cysteine peptidase inhibitors isolated from the human placenta both the neoplasm and VEGF concentration, which affect angiogenesis, tend to decrease.

Control of VEGF concentration and the use of cysteine peptidase inhibitors seem to complement one another. Taking advantage of the properties of cysteine peptidase inhibitors originating from the human placenta or chicken egg white, not only is it possible to control cysteine peptidase activity but also to reduce the concentration of VEGF and its receptors. Furthermore, a very significant growth of necrosis of the neoplastic tumour, which also decreased, was observed $[29,30]$.

The core purpose of the study was to show that it is possible to use in vitro cysteine peptidase inhibitors obtained from egg white as peptides controlling the 


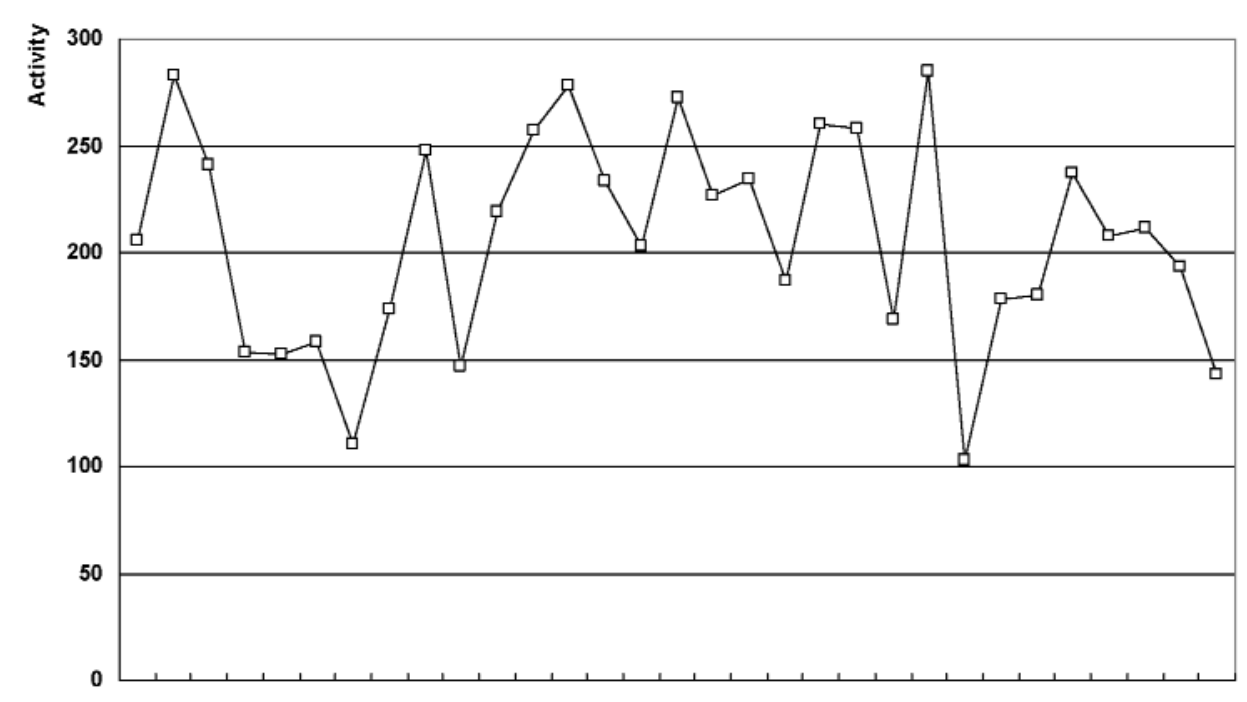

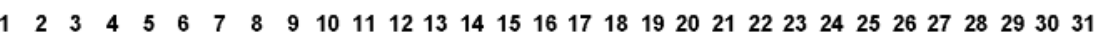

Sample No.

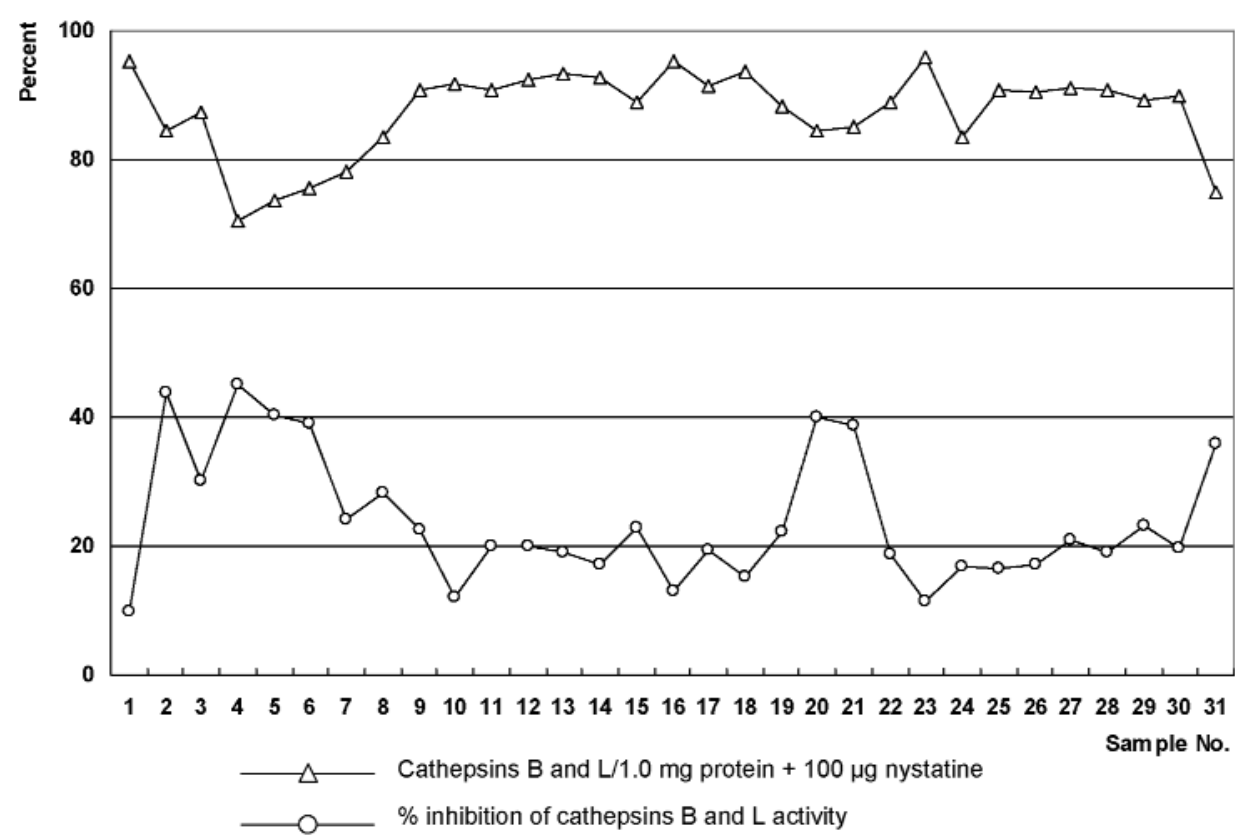

Fig. 1. Cathepsins B and L activity/1.0 mg protein

Fig. 2. Inhibition of cysteine peptidase activity in ascitic fluid.

activity of enzymes responsible for neoplastic processes in ascitic fluid of pancreatic cancer patients.

Our in vitro tests suggest that egg white cystatin, with a molecular weight of $13 \mathrm{kDa}$, may be added to ascitic fluid to arrest enzymatic neoplastic processes. Such a procedure may limit the penetration of the peptide through the peritoneal membrane. This will avoid the problem observed in the case of intraperitoneal treatment, when administered cytostatics or TIMP inhibitors are small synthetic molecules, which penetrate into the blood, causing the same reaction as during conventional chemotherapy [2].

It is hoped that by using such inhibitors egg white cystatin will not only arrest the activity of neoplastic cysteine peptidases in ascitic fluid but also in the very neoplastic tumour or metastatic locations that show overexpression of enzymes with high affinity to egg white cystatin. The arrest or removal from the body of cysteine peptidases may assist and complement the intended therapeutic treatments [31].

\section{Conclusions}

The idea of inhibition of cysteine peptidases in vivo holds the promise for future development of totally new generation of anticancer drugs, which could control such key processes as transformation, invasion, metastases, angiogenesis or apoptosis. Application of 
new direction of inhibitotherapy utilizing inhibitors of similar structure to their autogenous analogues through ascitic fluid may limit negative effects of toxicity of the administered drugs while retaining hope for their effective activity. Obtaining the answer to this question will be possible only after completion of the in vivo studies.

\section{References}

[1] Brown KM. Multidisciplinary approach to tumors of the pancreas and biliary tree. Surg Clin North Am. 2009:89:115-131.

[2] Adam RA, Adam YG. Malignant ascites: past, present and future. J Am Col Surg. 2004:198:999-111.

[3] Korc M. Pathways for aberrant angiogenesis in pancreatic cancer. Mol Cancer. 2003:2:1-8.

[4] Garcea G, Dennison AR, Pattenden CJ, Neal CP, Sutton CD, Berry DP. Survival following curative resection for pancreatic ductal adenocarcinoma. A systematic review of the literature. JOP. 2008;9(2):99-132.

[5] Chang MY, Sugarbaker DJ. Innovative therapies: intraoperative intracavitary chemotherapy. Thorac Surg Clin. 2004:14,549-556.

[6] Hribaschek A, Meyer F, Schneider-Stock R, Pross M, Ridwelski K, Lippert H. Comparison of intraperitoneal with intravenous administration of taxol in experimental peritoneal carcinomatosis. Chemotherapy. 2007:53:410-417.

[7] Rocha-Lima CM. New directions in the management of advanced pancreatic cancer: a review. Anticancer Drugs. 2008:19:435-446.

[ 8] Hribaschek A, Meyer F, Schneider-Stock R, Pross M, Ridwelski K, Lippert H. Comparison of intraperitoneal with intravenous administration of taxol in experimental peritoneal carcinomatosis. Chemotherapy. 2007:53:410-417.

[9] Rocha-Lima CM. New directions in the management of advanced pancreatic cancer: a review. Anticancer Drugs. 2008:19:435-446.

[10] Joyce JA, Hanahan D. Multiple roles for cysteine cathepsins in cancer. Cell Cycle. 2004:3:1516-1619.

[11] Kos J, Lah TT. Cysteine proteinases and their endogenous inhibitors: target proteins for prognosis, diagnosis and therapy in cancer (review). Oncol. 1998:Rep.5:1349-1361.

[12] Schmitt M, Janicke F, Graeff H. Tumor-associated proteases. Fibrynolysis. 1992;6:3-18.

[13] Mayer J, Schoenberg MH, Berg HG. Mechanism and role of trypsinogen activation in acute pancreatitis. Hepatogastroenterology. 1999;46:2757-2763.

[14] Saleh Y, Siewiński M, Kielan W, Ziółkowski P, Gryboś M, Rybka J. Regulation of cathepsin B and L expression in vitro in gastric cancer tissues by egg cystatin. J Exp Ther Oncol. 2003;3:319-324.

[15] Czyżewska J, Guzińska-Ustymowicz K, Kemona A, Bandurski R. The expression of matrix metalloproteinase 9 and cathepsin B in gastric carcinoma is associated with lymph node metastasis, but not with postoperative survival. Folia Histochem Cytobiol. 2008;46(1):57-64.

[16] Barrett AJ. Fluorimetric assays for cathepsin B and cathepsin $\mathrm{H}$ with methylcoumarylamide substrates. Biochem $\mathrm{J}$. 1980;187:909-912.
[17] Machleidt W, Thiele U, Laber B, Assfalg-Machleidt I, Esterl A, Wiegand G, Kos J, Turk V, Bode W. Mechanism of inhibition of papain by chicken egg white cystatin. Inhibition constants of N-terminally truncated forms and cyanogen bromide fragments of the inhibitor. FEBS Lett. 1989;243:234-238

[18] Frank NY, Schatton T, Frank MH. The therapeutic promise of the cancer stem cell concept. J Clin Invest. 2010;120:41-50.

[19] Greenberg JI, Cheresh DA. VEGF as an inhibitor of tumor vessel maturation: implications for cancer therapy. Expert Opin Biol Ther. 2009;9:1347-1356.

[20] Middleton G, Ghaneh P, Costello E, Greenhalf W, Neoptolemos JP. New treatment options for advanced pancreatic cancer. Expert Rev Gastroenterol Hepatol. 2008;2:673-696.

[21] Saif MW. Anti-angiogenesis therapy in pancreatic carcinoma. JOP. 2006;9:163-173.

[22] Cox JL. Cystatins and cancer. Front Biosci. 2009;14:463-474.

[23] Keppler D. Towards novel anti-cancer strategies based on cystatin function. Cancer Lett. 2006;235:159-176.

[24] Kuester D, Lippert H, Roessner A, Krueger S. The cathepsin family and their role in colorectal cancer. Pathol Res Pract. 2008;204:491-500.

[25] Chang SH, Kanasaki K, Gocheva V, Blum G, Harper J, Moses MA, Shih SC, Nagy JA, Joyce J, Bogyo M, Kalluri R, Dvorak HF. VEGF-A induces angiogenesis by perturbing the cathepsin-cysteine protease inhibitor balance in venules, causing basement membrane degradation and mother vessel formation. Cancer Res. 2009;69:4537-4544.

[26] Saleh Y, Siewiński M, Kielan W, Ziółkowski P, Gryboś M, Rybka J. Regulation of cathepsin B, L expression in vitro in gastric cancer tissues by egg white cystatin. $J$ Exp Ther Oncol. 2003;3(6):319-24.

[27] Saleh Y, Wnukiewicz J, Trziszka T, Siewiński M, Ziółkowski P, Kopeć W. Cathepsin B and cysteine protease inhibitors in human tongue cancer: Correlation with tumor staging and in vitro inhibition of cathepsin B by chicken cystatin. J Cancer Molecules. 2006;2:67-72.

[28] Saitoh E, Isemura S, Sanada K. Cystatin superfamily. Evidence that family II cystatin genes are evolutionary related to family III cystatin genes. Biol Chem Hoppe-Seyler. 1988;369:191-197.

[29] Saleh Y, Ziółkowski P, Siewiński M, Milach J, Marszalik P, Rybka J. The combined treatment of transplantable solid mammary carcinona in wistar rats by use photodynamic therapy and cysteine proteinase inhibbitors. In Vivo. 2001;15:351357.

[30] Zsebik B, Symonowicz K, Saleh Y, Ziółkowski P, Bronowicz A, Vereb G. Photodynamic therapy combined with a cysteine proteinase inhibitor synergistically decrease VEGF production and promote tumour necrosis in a rat mammary carcinoma. Cell Proliferation. 2007;40:38-49.

[31] Siewiński M, Bryjak M, Sebzda T, Całkosiński I, Gryboś M, Kilar E, Kumar Anil Agrawal, Choroszy-Król I, Janocha A, Pietkiewicz A, Trziszka T. A system and method for the extracorporeal purification of blood of pathogenic enzyme. Patent Cooperation Treaty (PCT) Medical University of Wrocław, Poland. 2007:PCT/PL2007/000060.

Submitted: 25 April, 2010 Accepted after reviews: 11 August, 2010 